Jennifer E. Mosley*

\title{
Nonprofit Organizations' Involvement in Participatory Processes: The Need for Democratic Accountability
}

DOI 10.1515/npf-2015-0038

\begin{abstract}
Participatory processes - defined as formal efforts to involve constituents in government decision-making - are an increasingly common tool adopted by public agencies and other elite decision making bodies in many developed nations. Unfortunately, although conceptualized as a way to incorporate lay citizens as stakeholders, participation in such processes takes time and expertise that many citizens do not have. As a result, nonprofit leaders are often invited to participate as a logistical shortcut for citizen involvement. This representation, albeit nonelected and unaccountable, is an increasingly important way vulnerable groups are represented and a key aspect of many nonprofit organizations' advocacy involvement. It is important to ask, then, how well nonprofits do when attempting to represent specific claimed constituents. It is likely their success varies greatly. While many organizations work to engage constituents in democratic ways - including ongoing outreach and communication strategies, establishing participatory mechanisms within their own organizations, and soliciting resident feedback - other nonprofits do not. Based on the authors' collaborative research, his brief identifies four specific policy proposals that may help facilitate the inclusionary goals of participatory processes, promote democratic accountability among nonprofit representatives, and make sure the needs of vulnerable citizens are met.
\end{abstract}

Keywords: participatory processes, democracy, nonprofits, community, accountability

Participatory processes - defined as formal efforts to involve constituents in government decision-making - are an increasingly common tool adopted by public agencies and other elite decision making bodies in many developed

*Corresponding author: Jennifer E. Mosley, School of Social Service Administration, University of Chicago, 969 E 60th St., Chicago, IL 60637, USA, E-mail: mosley@uchicago.edu 
nations. Conceived as a way to make government more accountable and more responsive to its citizens, these processes include task forces, advisory boards, and community councils. Participatory processes are thought to promote individual political engagement, while also increasing policy effectiveness and promoting government accountability (Barber 1984; Bingham, Nabatchi, and O'Leary 2005; Gastil 2000). In the U.S., these processes are used in the fields of health care (Mitton et al. 2009), the environment (Newig and Fritsch 2009), and poverty reduction (McGee and Norton 2000), among others.

Unfortunately, although conceptualized as a way to incorporate lay citizens as stakeholders, participation in such processes takes time and expertise that many citizens do not have. Interest is often low and it is hard for the designers of such processes to know who or how to recruit. This is particularly true for lowincome or hard-to-reach individuals or members of marginalized communities. As a result, nonprofit leaders are often invited to participate as a logistical shortcut for citizen involvement. Representatives of nonprofit organizations are often seen as established leaders in the community, they are easily identifiable, and are often presumed to have unique knowledge about community needs. Research has shown a wide variety of nonprofit organizations are involved in participatory processes including neighborhood associations (Logan and Rabrenovic 1990), community based organizations (Cnaan 1991), religious congregations (Owens 2007), and social service organizations (Mosley and Grogan 2013). This representation, albeit nonelected and unaccountable, is an increasingly important way vulnerable groups are represented and a key aspect of many nonprofit organizations' advocacy involvement.

These processes take different forms. Some are "open” processes, intended to solicit a wide variety of viewpoints from anyone who takes the time to participate. Others are "invited" processes, where government administrators design the process and invite specific individuals to participate. It is these invited processes that often involve nonprofit representatives and thus are the concern of this paper. When leaders of nonprofit organizations are invited to participate, it is sometimes unclear exactly what role they are expected to play. Are they there to share their own expertise and opinions? To communicate the perspective of their organization? Or are they being invited as a representative of a specific target group (e.g. children, people living with disabilities, people who are homeless), identity group (e.g. women, people of color, LGBT populations), or geographic community? Some public administrators would say that they want both out of nonprofit participants - the expertise that comes from being a nonprofit leader and a voice that is able to legitimately represent community concerns.

Speaking for yourself or the organization you lead is something nonprofit leaders are well-prepared to engage in. It is much less clear, however, how well 
nonprofits do when attempting to represent specific claimed constituents. It is likely their success varies greatly. While many organizations work to engage constituents in democratic ways - including ongoing outreach and communication strategies, establishing participatory mechanisms within their own organizations, and soliciting resident feedback - other nonprofits do not. This may be true even of large, professionalized social service agencies, or historically important religious organizations that often get seen as "leaders" in low-income communities of color.

For those organizational leaders tasked with representing a group of people larger than themselves, there are reasons to believe that legitimately representing the interests of a specific community is a daunting task. Communities contain significant diversity, including different opinions about needs, priorities, and appropriate responses. Meanwhile, organizations have competing priorities themselves. Nonprofit managers need to maintain accountability to stakeholders beyond community members and consumers, including funders, board members, and staff members. Finally, organizational leaders may disagree with community sentiment on important issues or simply have a different perspective and priorities (Kissane and Gingerich 2004).

\section{Connection to Current Research}

Over the past 5 years, my University of Chicago colleague Colleen Grogan and I have engaged in a multi-method study that addresses to what extent and how well nonprofit community-based organizations represent vulnerable communities - from the perspective of both residents and the organizations that represent them. We have focused on three research questions in regards to residents: (1) Do residents believe nonprofit community-based organizations can play a legitimate representational role? (2) What organizational characteristics or behaviors do residents see as important determinants of legitimate representation? and (3) Do residents view certain types of organizations as better embodying these elements of legitimate representation? These questions have then been paired with two research questions addressing the activity of nonprofit organizations: (1) How do nonprofit leaders conceptualize their representative role in participatory processes? (2) How might different conceptions of what is "good" representation influence how leaders carry out representative activities? All of this work has been carried out in low-income, primarily AfricanAmerican neighborhoods on the Southside of Chicago.

In a recent survey of the population of nonprofit organizations in three Chicago neighborhoods, we found that most nonprofit leaders are involved in 
some kind of representative activity, and involvement in participatory processes is high, even among small organizations that do not otherwise engage in advocacy. However, nonprofit representatives differ in their view of whom they actually represent. For example, we find many religious leaders believe they are only responsible for voicing the needs of their congregation, while human service leaders often believe they speak for the larger community. Our findings also suggest one cannot assume that nonprofits are in active communication with the residents they represent: most organizations had only minimal processes in place to exchange information with residents around their representational activity. However, our previous work (Mosley and Grogan 2012) indicates this is crucial for building trust with residents. In a qualitative study of residents' perceptions of nonprofit representational activity, we find that attention to democratic processes was recognized and strongly desired by community members and a key element of building trust. Two-way communication builds trust by demonstrating both transparency and openness to learning. A focus on producing concrete benefits (outcomes) was also mentioned by residents as an important element of legitimate representation. Such outcomes generally include material resources flowing to the community, such as a new program, park, or event. Since organizations clearly differ in their orientation to both process and outcomes, these findings help inform how selection procedures for participatory processes can be designed in ways that advance legitimate representation.

\section{Specific Policy Proposals}

Based on the background and research presented above, I identify four specific policy proposals. These proposals are designed with an eye to facilitating the inclusionary goals of participatory processes, promoting democratic accountability among nonprofit representatives, and making sure the needs of vulnerable citizens are met. They are applicable to invited processes, where nonprofit organizations are being asked to represent the interests of a specific group or community.

(1) Government administrators responsible for designing participatory processes should prefer nonprofit participants that have a demonstrated commitment to democratic principles in their own organization. Evidence of such commitment might include having community residents sit on their board, having resident advisory boards, or other processes in place to ensure transparent decision-making. The risk to such a proposal is that if government sets a "floor" for what is expected in the way of democratic 
engagement within organizations, it may result in organizations treating that floor like a ceiling. Of course, given the rarity of inclusive practices in the organizations we surveyed, such a floor would still be an improvement over current practices.

(2) A variety of nonprofit participants should be chosen to participate and designers should be aware that large nonprofits with seemingly long histories in a community are not always well informed about the concerns of the current community. Communities are diverse and so should be the organizations that represent them. Of course small organizations often find participation challenging because of low capacity, and may be difficult for designers to identify in the first place. Like citizens, often the reasons why we want organizations to participate (e.g. they face distinctive challenges or have unique perspectives) are the same reasons why it is difficult for them to participate. Thus, along with inviting diverse organizations and perspectives, designers should also pay attention to the costs of participation, making sure that time and resource constraints don't inadvertently limit the types of organizational leaders than can participate.

(3) Nonprofits that participate in participatory processes should be held accountable to democratic principles by being encouraged and supported in their efforts to (a) return information to community members and (b) involve community residents in participatory forums directly. This should result in a feedback loop between organizations and residents, so that organizations can carry out representation legitimately and are accountable to residents in some fashion.

(4) Even if the above is accomplished, the work of engaging community members can easily become primarily ceremonial. Nonprofit leaders and government administrators should recognize this risk as well as the difficulty in doing this work in order to put the appropriate incentives in place for meaningful action. This may call for more government funding support specifically for civic engagement. It also suggests the need for experiments that can help determine more effective (in the eyes of residents) and efficient (in the eyes of organizations) ways of engaging community members. For example, the growth of social media technology is an alternative way to get participation and feedback directly from residents, and does not require a burdensome time commitment.

These proposals are all of the top-down variety, recognizing that public administrators are generally driving participatory process design and, as such, have both the greatest responsibility and ability to affect decision-making. That said, there are risks to putting the onus on the government to understand these issues and 
implement them appropriately. Important critiques of participatory processes in general are that they can be more about "optics" then action, or that they are a form of co-optation. In addition, when concepts such as "democratic accountability" and "organizational diversity" get operationalized in specific ways, they can quickly become calcified and meaningless. Encouraging more nonprofit selfregulation on these issues may be an alternative strategy, though without incentives stemming from the processes themselves, efforts may be weak.

\section{Conclusion}

Nonprofits are important and valued partners in state and local government decision-making. Participating in collaborative processes, on behalf of the communities they serve, underlines the role of nonprofits as key civic intermediaries and is one of the many ways that nonprofits mediate the relationship between citizens and government. Finding ways to more fully integrate them in decisionmaking processes is important in order to make government more accountable to constituents. However, policy should recognize that nonprofit organizations are often being selected into such processes in lieu of citizens, and address more explicitly the degree to which nonprofits adequately represent community interests. Policy solutions that fruitfully encourage nonprofit organizations to be more explicitly democratic in their interactions with constituents have the potential to improve government decision-making and reduce political inequality in diverse communities.

\section{References}

Barber, Benjamin R. 1984. Strong Democracy: Participatory Politics for a New Age. Berkeley, CA: University of California Press.

Bingham, Lisa B., Tina Nabatchi, and Rosemary O’Leary. 2005. “The New Governance: Practices and Processes for Stakeholder and Citizen Participation in the Work of Government."

Public Administration Review 65:547-58.

Cnaan, Ram A. 1991. "Neighborhood-Representing Organizations: How Democratic Are They?" Social Service Review 65 (4):614-34.

Gastil, John. 2000. By Popular Demand: Revitalizing Representative Democracy Through Deliberative Election. Berkeley, CA and Los Angeles, CA: University of California Press.

Kissane, Rebecca J., and Jeff Gingerich. 2004. "Do You See What I See? Nonprofit and Resident Perceptions of Urban Neighborhood Problems." Nonprofit and Voluntary Sector Quarterly 33:311-33.

Logan, John R., and Gordana Rabrenovic. 1990. "Neighborhood Associations: Their Issues, Their Allies and Their Opponents.” Urban Affairs Quarterly 26 (1):68-94. 
McGee, Rosemary, and Andy Norton. 2000. Participation in Poverty Reduction Strategies:

A Synthesis of Experience with Participatory Approaches to Policy Design, Implementation and Monitoring, IDS Working Paper 109. Brighton: Institute of Development Studies.

Mitton, Craig, Neale Smith, Stuart Peacock, Brian Evoy, and Julia Abelson. 2009. "Public Participation in Health Care Priority Setting: A Scoping Review.” Health Policy 91 (3):219-28.

Mosley, Jennifer E., and Colleen M. Grogan. 2013. "Representation in Nonelected Participatory Processes: How Residents Understand the Role of Nonprofit Community-Based Organizations." Journal of Public Administration Research and Theory 23 (4):839-63.

Newig, Jens, and Oliver Fritsch. 2009. "Environmental Governance: Participatory, Multi-Level-and Effective?” Environmental Policy and Governance 19 (3):197-214.

Owens, Michael Leo. 2007. God and Government in the Ghetto: The Politics of Church State Collaboration in Black America. Chicago: University of Chicago Press. 